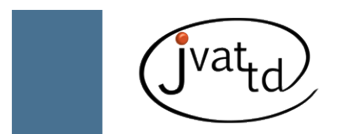

\title{
Allium species poisoning in dogs and cats
}

Salgado BS (1), Monteiro LN (2), Rocha NS (1, 2)

(1) Department of Pathology, Botucatu Medical School, São Paulo State University (UNESP - Univ Estadual Paulista), Botucatu, São Paulo State, Brazil; (2) Department of Veterinary Clinical Sciences, Veterinary Pathology Service, School of Veterinary Medicine and Animal Husbandry, São Paulo State University (UNESP - Univ Estadual Paulista), Botucatu, São Paulo State, Brazil.

\begin{abstract}
Dogs and cats are the animals that owners most frequently seek assistance for potential poisonings, and these species are frequently involved with toxicoses due to ingestion of poisonous food. Feeding human foodstuff to pets may prove itself dangerous for their health, similarly to what is observed in Allium species toxicosis. Allium species toxicosis is reported worldwide in several animal species, and the toxic principles present in them causes the transformation of hemoglobin into methemoglobin, consequently resulting in hemolytic anemia with Heinz body formation. The aim of this review is to analyze the clinicopathologic aspects and therapeutic approach of this serious toxicosis of dogs and cats in order to give knowledge to veterinarians about Allium species toxicosis, and subsequently allow them to correctly diagnose this disease when facing it; and to educate pet owners to not feed their animals with Alliumcontaing food in order to better control this particular life-threatening toxicosis.
\end{abstract}

Key words: Allium spp., poisonous plants, hemolytic anemia, Heinz bodies.

\section{INTRODUCTION}

The genus Allium includes onion, garlic, leek, chives, shallots, and scallions, and was previously classified in the family Alliaceae (1). However, in the new classification of Angiosperm Phylogeny Group, Alliaceae is now the subfamily Allioideae of the family Amaryllidaceae (2). Some botanical authorities have also previously included it in the lily family (Lilliaceae) $(3,4)$.

The Allium genus comprises biannual bulbous plants that grow in the north hemisphere except for a few species found in South America and Tropical Africa (5) (Table 1). These plants form solitary or clustered bulbs and are strongly aromatic, with a characteristic odor when crushed. This distinctive aroma is thought to be related to allicin and other oil-soluble sulfurcontaining organic compounds that allow us to differentiate them from other morphologically similar poisonous plants $(6,7)$.

Wild and domestic Allium species have been used as ingredients in many dishes and with ethnomedical purposes for many years. This plant is rich in two chemical groups that are thought to provide benefits to human health: flavonoids and alk(en)yl cysteine sulfoxides. Apart from its culinary uses (fresh, cooked or dehydrated), medicinal properties have been attributed it since ancient times, prompting in recent years an accurate chemical analysis of its most characteristic active components (7-10). Compounds from onions have a range of health benefits such as anticarcinogenic, antiplatelet, antithrombotic, antiasthmatic, antidiabetic, fibrinolytic and hypocholesterolemic properties, and other various biological actions including antibiotic effects (11-13). 
Table 1. Subdivision, horticultural names, and origin of important cultivated Allium species

\begin{tabular}{|c|c|c|c|}
\hline Species & Subdivision & Horticultural name & Origin \\
\hline \multirow{4}{*}{ Allium cepa } & сера & Bulb onion & \multirow{4}{*}{ Asia } \\
\hline & ascalonium & Shallot & \\
\hline & aggregatum & Potato onion & \\
\hline & proliferum & Tree onion & \\
\hline Allium sativum & - & Garlic & Asia \\
\hline \multirow{2}{*}{ Allium ampeloprasum } & porrum & Leek & \multirow{2}{*}{$\begin{array}{c}\text { Eurasia and } \\
\text { Africa }\end{array}$} \\
\hline & aegyptiacum & Kurrat & \\
\hline Allium schoenoprasum & - & Chives & Europe \\
\hline Allium chinense & - & Rakkyo & Asia \\
\hline Allium fistulosum & - & $\begin{array}{c}\text { Japanese bunching (Welsh } \\
\text { onion) }\end{array}$ & Asia \\
\hline Allium tuberosum & - & Chinese chives & Asia \\
\hline
\end{tabular}

All Allium species and their derivatives can be toxic to dogs and cats (14-20). However, relatively few Allium species are of important toxicological interest. Domestic species that are more commonly involved in poisoning are onion (Allium cepa) (Figure 1), garlic (Allium sativum) (Figure 2), leek (Allium porum) (Figure 3 ), and chives (Allium schoenoprasum) (Figure 4). Onions contain toxic components that may damage red blood cells and provoke hemolytic anemia accompanied by the formation of Heinz bodies in erythrocytes of animals such as cattle, water buffaloes, sheep, horses, dogs, and cats (14-29).

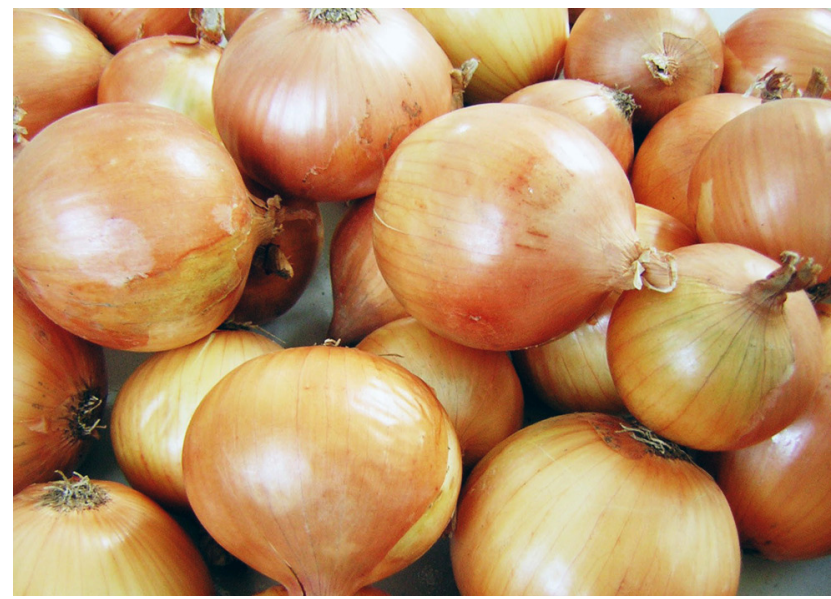

Figure 1. Bulb onion (Allium cepa).
Plant poisoning is not a usual disease in dogs and cats, since plants are not a common compound of their diet. However, they often cause acute life-threatening conditions and represent an imminent cause of death in those animals. Accordingly, the present review aim to discuss aspects related to one particular plant poisoning: Allium species toxicosis.

Since those plants are culturally present in the Brazilian gastronomy and can be easily accessible to pets, consequently leading to the development of important clinical problems, essential features of Allium species toxicosis are discussed herein in order to sensitize veterinarians to the possibility of facing similar cases and to prepare them for readily diagnose and treat affected animals.

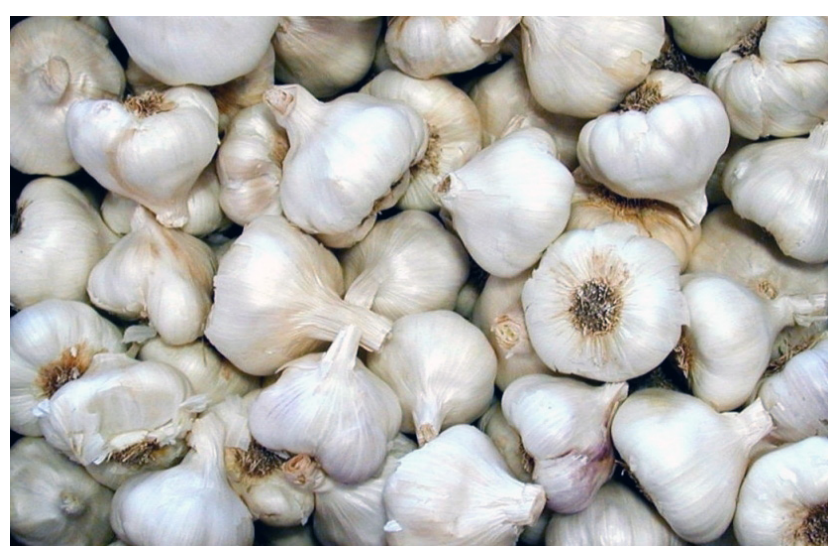

Figure 2. Garlic (Allium sativum). 


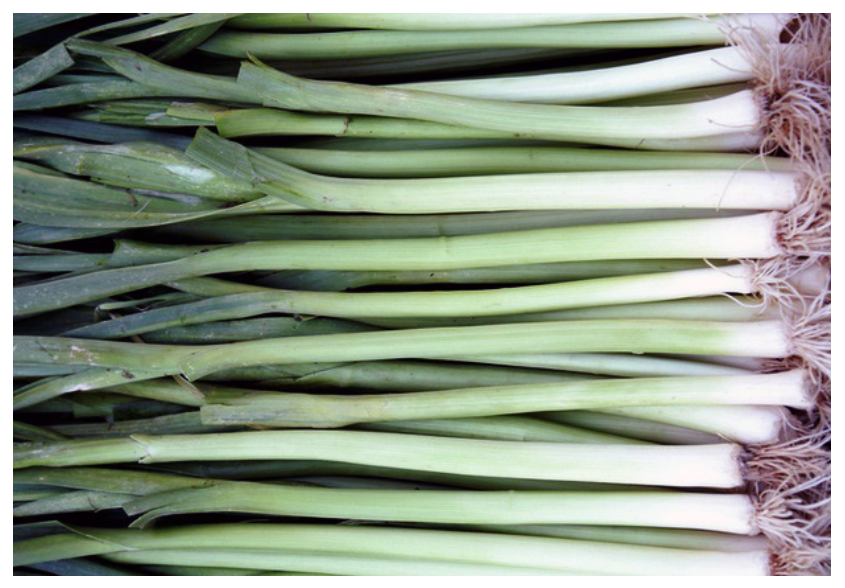

Figure 3. Leek (Allium porrum).

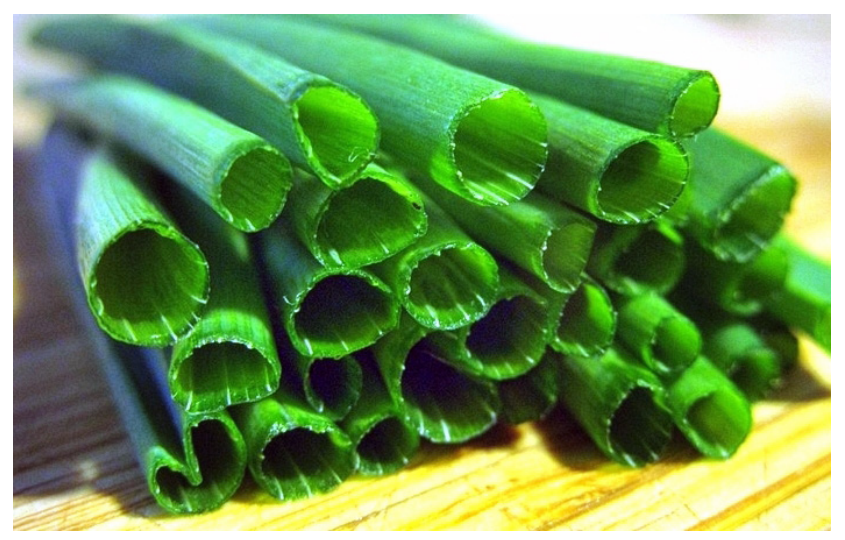

Figure 4. Chives (Allium schoenoprasum).

\section{TOXICITY}

Allium species contain various organosulfoxides, particularly alk(en)yl cysteine sulfoxides, some of which are responsible for their characteristic odor $(7,9)$. Plant trauma (e.g. chewing or cutting) converts the organosulfoxides to a complex mixture of sulfur-containing organic compounds that are responsible for the flavor and effects of these plants on animals (30). Many Allium organosulfur compounds appear to be readily absorbed through the gastrointestinal tract and are metabolized to highly reactive oxidants (6).

Di-propyl-disulfide $\left(\mathrm{H}_{7} \mathrm{C}_{3} \mathrm{~S}_{2} \mathrm{C}_{3} \mathrm{H}_{7}\right)$ and allyl propylisulfide $\left(\mathrm{H}_{5} \mathrm{C}_{3} \mathrm{~S}_{2} \mathrm{C}_{3} \mathrm{H}_{7}\right)$ have been implicated in onion-induced hemolytic anemia (30-34). However, recently, more active oxidizing sulfurcontaining compounds have been discovered and proposed as causative agents, either in onion or garlic poisoning episodes $(20,35)$. Sodium $\mathrm{n}$-propylthiosulfate, isolated from boiled onions, was proven to cause an increase of Heinz body formation in erythrocytes and subsequent hemolytic anemia in dogs (36).

Garlic, on the other hand, is considered to be less toxic and safe for dogs than onion when used in moderation (37).

\section{ACTION MECHANISM}

The primary toxicological mechanism of Allium-derived organosulfur compounds is oxidative hemolysis, which occurs when the concentration of oxidants in the erythrocyte exceeds the capacity of the antioxidant metabolic pathways. Catalase antioxidant activity in dog erythrocytes is low, and normal hemoglobin in cats is about two to three times more susceptible to oxidative damage than the hemoglobin in other species $(38,39)$.

N-propyl disulfide and sodium n-propylthiosulfate are very poisonous organosulfur compounds present in onions. The former may cause a marked decrease in the activity of glucose-6-phosphate dehydrogenase (G6PD), whereas the latter can increase the methemoglobin concentration and Heinz body count in erythrocytes, and reduce glutathione concentration in the erythrocyte $(30,40,41)$. In erythrocytes, G6PD oxidizes glutathione to a reduced form through the pentose phosphate pathway $(39,42,43)$. When the activity of G6PD is decreased, the content of glutathione also drops, leading to increased levels of hydrogen peroxide. It is known that lipid peroxidation can be determined by malondialdehyde formation (44). Consequently, hydrogen peroxide and malondialdehyde oxidize the sulfhydryl groups of hemoglobin, resulting in the denaturation of hemoglobin (30).

Additionally, oxidation of the exposed $\beta-93$ cysteine residues present in hemoglobin results in sulfhemoglobin formation (45). Sulfhemoglobin and denatured hemoglobin are less soluble than normal hemoglobin, so they precipitate, aggregate, and bind to the cell membrane and form Heinz bodies. Other types of oxidation of hemoglobin globin chains result in membrane cross-linking reactions and eccentrocyte formation (46). The formation of Heinz bodies and eccentrocytes increases erythrocyte fragility and extravascular hemolysis, since erythrocytes that contain Heinz bodies are removed from the circulation by the reticuloendothelial system, thus causing 
anemia. Damaged erythrocytes are removed from circulation, causing hemoglobinemia and hemoglobinuria $(6,47)$.

Direct oxidative damage to the erythrocyte cell membrane and its sodium-potassium pump or the oxidative production of hemin also contribute to cell lysis. Oxidation of the heme ion and associated methemoglobinemia result in a left shift of the hemoglobin-oxygen dissociation curve, decreased blood oxygen transportation capacity, and, ultimately, impaired delivery of oxygen to tissues $(48,49)$.

Thus, the result of the oxidative hemolytic process induced by Allium consumption is the onset of anemia, methemoglobinemia, and impaired oxygen transportation. Although marked Heinz body formation may be present within a day after onions are ingested, the anemic nadir typically develops several days later (49).

Allicin and ajoene, pharmacologically active agents in garlic, are potent cardiac and smooth muscle relaxants, vasodilators, and hypotensive agents (50-52). Also, ajoene and other organosulfur compounds derived from onions are potent antithrombotic agents (53). Thus, hypotensive and antithrombotic properties can exacerbate the physiologic effects of anemia and impaired oxygen transportation. Garlic preparations that have not been aged cause direct damage to the gastric and ileal mucosa, resulting in pain and diarrhea (54).

\section{EXPOSURE AND SUSCEPTIBILITY}

Allium toxicosis commonly occurs after ingestion. In addition to consuming fresh plant material, juice, fresh and dietary supplements, powdered cooking preparations, dehydrated material, or food preparations derived from or containing Allium species can be potentially toxic to dogs and cats $(37,49)$. This type of toxicosis is typically caused by consumption of a single large quantity of plant material or repeated small amounts. Dogs and cats are highly susceptible to onion toxicosis, consumption of as little as $5 \mathrm{~g} / \mathrm{kg}$ of onions for cats or 15 to $30 \mathrm{~g} / \mathrm{kg}$ for dogs resulted in clinically important hematologic changes. Onion toxicosis is consistently noted in animals that ingest more than $0.5 \%$ of their body weight in onions at one time (49). A relatively high dose (600-800 g) in one meal or spread apart over a few days can damage red blood cells and cause hemolytic anemia accompanied by the formation of Heinz bodies in erythrocytes (37).

Dogs with hereditary high erythrocyte reduced glutathione and circulating potassium level are more susceptible to the hematologic effects of onions $(36,55)$. This trait is relatively common in Japanese breeds, such as Akita inu and Shiba inu. Other inborn errors in metabolism or nutritional deficiencies that result in decreased erythrocyte antioxidant defenses, such as glucose-6-phosphate dehydrogenase deficiency or zinc deficiency, could increase an animal's susceptibility to Allium toxicosis (56).

The oral administration of $500 \mu \mathrm{mol}$ per kilogram of body weight of sodium n-propylthiosulfate to dogs results in hemolytic anemia associated with increased Heinz body formation in erythrocytes, which is more severe in dogs with the hereditary condition, which, in turns, results in erythrocytes with high concentrations of reduced glutathione and potassium than in normal dogs. In affected dogs there is a ten-fold increase in the concentration of oxidized glutathione in their erythrocytes 12 hours after the administration of the compound, whereas in normal dogs there is almost no change (36).

Humans are the most resistant species studied. On the other hand, there is some concern about the susceptibility of certain ethnic groups that have a genetic deficiency of glucose-6-phosphate dehydrogenase. Although dogs appear to be one of the most susceptible species, there are a few reports in the literature concerning accidental canine poisoning associated with onion ingestion.

Cats are more susceptible than dogs. Since baby food is often offered to sick animals that are not eating (to stimulate their appetite), there is some concern that the onion powder would cause a Heinz body anemia in these cats (57). Several baby food manufacturers add onions or onion powder to increase palatability.

It is generally accepted that sheep, goats, rats and mice are more resistant to onion toxicosis than other domestic animals $(27,48)$. The safety of feeding onions to livestock depends upon animal susceptibility and the toxic potential of the plant species. Sheep can be maintained on diets of up to $50 \%$ onions with no clinical abnormalities or detrimental effects on growth. Even when onions are fed free choice, sheep have only transient hemoglobinuria and anemia, with few deaths 
reported. In contrast, cattle should be fed onions with caution, due to the relative susceptibility of their erythrocytes to oxidative damage. Daily feeding of onions could have a cumulative effect due to ongoing formation of Heinz bodies versus a single exposure with a wide gap until the next exposure, allowing the bone marrow to regenerate the prematurely destroyed red cells (37).

Concurrent treatment with xenobiotics, drugs, or dietary factors that induce erythrocyte oxidative injury (e.g. propofol, propylene glycol, dl-methionine, sulfonamides, sulfapyridine, large doses of vitamin K3, benzocaine) or diminish erythrocyte oxidative defenses (e.g. acetaminophen) is likely to increase an animal's susceptibility to Allium species toxicosis (49).

\section{CLINICAL SIGNS}

In dogs and cats, clinical signs of Allium species toxicosis may appear within one day of consumption if large amounts of material have been ingested. However, it is more common the development of clinical signs after a lag of several days (49). The first signs are usually of gastroenteritis: vomiting, diarrhea, abdominal pain, loss of appetite, depression and dehydration. It will take a few days for the dog to display the signs associated with the loss of red blood cells: pale mucous membranes, rapid respiratory rate, difficulty to breathe, lethargy, dark colored urine (reddish or brown), jaundice, weakness, and rapid heart rate (37). Depression, hemosiderin in urine, exercise intolerance and cold sensitivity may also be observed (49). In cases of recent ingestion, the breath of the affected dog or cat may smell like onions or garlic (16).

\section{CLINICAL PATHOLOGY}

Clinical pathology findings are consistent with intravascular and extravascular hemolysis, anemia, hemoglobinemia, hemoglobinuria associated with hemoglobin casts in urine and hemosiderin, hyperbilirubinemia, methemoglobinemia, and, if the animal survives long enough, an accompanying regenerative response (49). Hematologic tests may reveal neutrophilia, lymphopenia, Heinz-body anemia and methemoglobinamia (37).

Heinz body formation, eccentrocytosis, and a decrease in erythrocyte glutathione levels can also be detected. Additionally, eccentrocytosis appear to be one of the major diagnostic features of garlic-induced hemolysis in dogs $(20,46)$.

\section{ANATOMIC PATHOLOGY}

Necropsy and histological findings typically indicate hemolytic anemia. Because of the lag of several days between ingestion and the development of clinical signs, gastrointestinal erosion or Allium in the gut content may not be seen (49). Necropsy findings basically consists of splenomegaly due to hemosiderosis and increased hemocatheresis, and jaundice due to the hemolytic anemia provoked, in turn, by extravascular hemolysis $(19,58,59)$.

Histopathologic findings, although consistent with hemolytic anemia, are not specific for Allium toxicosis and may include deposition of hemosiderin in the phagocytic cells of the liver, spleen, and renal tubular epithelium; renal tubular pigment necrosis; and nephrotubular casts and hemoglobin casts in the renal tubules $(58,59)$.

\section{DIFFERENTIAL DIAGNOSES}

Heinz bodies comprise an uncommon finding in dogs that can only be induced by a few other toxicoses, such as methilen blue, acetaminophen, benzocaine, vitamin $\mathrm{K} 3$, zinc and phenylhidrazine $(32,60,61)$. In such cases, Allium toxicosis should always be included in the differential diagnosis (34).

Common feline disorders associated with Heinz body formation include diabetes mellitus, particularly if ketoacidosis is present; hepatic lipidosis, hyperthyroidism; and neoplasms such as lymphoma (49). Jaundice-causing infections such as babesiosis and leptospirosis should also be included in the differentials. Additionally, posthepatic obstructions should also be speculated due to its jaundice-causing effects.

\section{TREATMENT}

No specific antidote is available for Allium toxicosis; however, supportive care may be helpful including hospitalization, administration of intravenous fluids and blood transfusions. Treatment is indicated after ingestion of any quantity (37). Several therapeutic approaches have been suggested to treat onion-poisoned animals, 
including gastrointestinal decontamination, administration of antioxidant vitamins (C and $\mathrm{E}$ ) (in dogs, ascorbic acid $-30 \mathrm{mg} / \mathrm{kg}$ of body weight intravenously, each 6 to 8 hours) or $\mathrm{N}$-acetylcysteine, and intravenous fluid therapy or blood transfusions, but none has proven really effective (31, 34, 62). Nevertheless, even taking into account that lethal effects are infrequent in dogs, avoiding animal exposure to any kind of onion seems to be the best preventive health strategy $(15,31,34)$.

Induction of emesis (e.g. apomorphine 0.08 $\mathrm{mg} / \mathrm{kg}$ intramuscularly or subcutaneously, or $3 \%$ hydrogen peroxidase $2 \mathrm{~mL} / \mathrm{kg}$, no more than 45 $\mathrm{mL}$ ) can be valuable in asymptomatic dogs and cats that showed no complicating factors one or two hours after the ingestion. Administration of activated charcoal ( 1 to $4 \mathrm{~g} / \mathrm{kg}$ per oral) is indicated after emesis. In severely affected animals, a blood transfusion and supplemental oxygen therapy may be required. Administration of intravenous crystalloids is indicated if extensive vomiting and diarrhea occurred or if hemoglobinuria or hypotension is evident (49).

\section{CONCLUDING REMARKS}

The ingestion of Allium species by various animals may lead to toxicosis; however, dogs and cats deserve special attention since they are most susceptible. Allium toxicosis is typically diagnosed through a combination of history, clinical signs, and microscopic confirmation of a Heinz body-type hemolytic anemia that if is quickly performed can allow veterinarians to give a support treatment in order to avoid animal death. It is important to carefully monitor the erythron of affected animals for several days after ingestion since it is when the anemic nadir usually occurs. Antioxidants - such as sodium ascorbate, vitamin E, and acetylcysteine - have minimal protective effects on onion powder toxicosis in cats (62). Diets with low potential oxidants are recommended; semimoist food that contains propylene glycol should be avoided, particularly for cats (63).

Additionally, it is also important to educate pet owners to not feed their animals with Alliumcontaing food and not to store Allium in places accessible to their pets; these measures may lead, in long term, to a better control of this particular life-threatening toxicosis.

\section{COPYRIGHT}

(c) CEVAP 2011

\section{SUBMISSION STATUS}

Received: June 11, 2010.

Accepted: October 26, 2010.

Abstract published online: November 5, 2010.

Full paper published online: February 28, 2011.

\section{CONFLICTS OF INTEREST}

There is no conflict.

\section{CORRESPONDENCETO}

BRENO SOUZA SALGADO, Departamento de Patologia, Faculdade de Medicina de Botucatu, UNESP, Distrito de Rubião Jr., s/n, Botucatu, São Paulo, SP, 18618-970, Brasil. Phone/fax: +55 14 3811 6293. Email: brenosalgado@globo.com.

\section{REFERENCES}

1. Friesen N, Fritsch RM, Blattner FR. Phylogeny and new intrageneric classification of Allium (Alliaceae) based on nuclear ribosomal DNA its sequences. Aliso. 2006;22(1):372-95.

2. Angiosperm Phylogeny Group III. An update of the Angiosperm Phylogeny Group classification for the orders and families of flowering plants: APG III. Bot J Linn Soc. 2009;161(2):105-21.

3. Woodward P. Garlic and friends: the history, growth and use of edible Alliums. Melbourne: Hyland House; 1996. 248 p.

4. Fritsch RM, Friesen N. Evolution, domestication and taxonomy. In: Rabinowitch HD, Currah L, editors. Allium crop science: recent advances. Wallingford: Cab International; 2002. p. 5-30.

5. Griffiths G, Trueman L, Crowther T, Thomas B, Smith B. Onions - a global benefit to health. Phytother Res. 2002;16(7):603-15.

6. Amagase H, Petesch BL, Matsuura H, Kasuga S, Itakura Y. Intake of garlic and its bioactive components. J Nutr. 2001;131(3s):955S-62S.

7. Jones MG, Hughes J, Tregova A, Milne J, Tomsett AB, Collin HA. Biosynthesis of the flavour precursors of onion and garlic. J Exp Bot. 2004;55(404):1903-18.

8. Arnault I, Auger J. Seleno-compounds in garlic and onion. J Chromatogr A. 2006; 1112(1-2):23-30.

9. Lanzotti V. The analysis of onion and garlic. J Chromatogr A. 2006;1112(1-2):3-22.

10. Santas J, Carbó R, Gordon MH, Almajano MP. Comparison of the antioxidant activity of two Spanish onion varieties. Food Chem. 2008;107(3):1210-6.

11. Augusti KT. Therapeutic values of onion (Allium cepa L.) and garlic (Allium sativum L.). Indian J Exp Biol. 1996;34(7):634-40.

12. Briggs WH, Folts JD, Osman HE, Goldman IL. Administration of raw onion inhibits platelet-mediated thrombosis in dogs. J Nutr. 2001;131(10):2619-22. 
13. Slimestade R, Fossen T, Vagen IM. Onions: a source of unique dietary flavonoids. J Agric Food Chem. 2007;55(25):10067-80.

14. Kobayashi K. Onion poisoning in the cat. Feline Pract. 1981;11(1):22-7.

15. Stallbaumer M. Onion poisoning in a dog. Vet Rec. 1981;108(24):523-4.

16. Harvey JW, Rackear D. Experimental onion-induced hemolytic anemia in dogs. Vet Pathol. 1985;22(4):38792.

17. Smith $\mathrm{CH}$, Ellison RS. Concurrent onion poisoning and haematuria in a dog. N Z Vet J. 1986;34(5):77-8.

18. Solter P, Scott R. Onion ingestion and subsequent Heinz body anemia in a dog: a case report. J Am Anim Hosp Assoc. 1987;23(5):544-6.

19. Fighera RA, Souza TM, Langohr I, Barros CSL. Intoxicação experimental por cebola, Allium cepa (Liliacea) em gatos. Pesq Vet Bras. 2002;22(2):79-84.

20. Yamato O, Kasai E, Katsura T, Takahashia S, Shiota T, Tajima M, et al. Heinz body hemolytic anemia with eccentrocytosis from ingestion of Chinese chive (Allium tuberosum) and garlic (Allium sativum) in a dog. J Am Anim Hosp Assoc. 2005; 41(1):68-73.

21. Desnoyers M. Anemias associated with Heinz bodies. In: Fedman BF, Zinkl JG, Jain NC, editors. Schalm's veterinary hematology. 5th ed. Baltimore: Lippincott Williams \& Wilkins; 2000. p. 178-80.

22. Hutchinson TW. Onions as cause of Heinz body anemia and death in cattle. Can Vet J. 1977;18(12):35860.

23. Carbery JT. A case of onion poisoning in a cow. $\mathrm{N} \mathrm{Z}$ Vet J. 1999;47(5):184.

24. Rae HA. Onion toxicosis in a herd of beef cows. Can Vet J. 1999;40(1)55-7.

25. van der Kolk JH. Onion poisoning in a herd of dairy cattle. Vet Rec. 2000; 147(18):517-8.

26. Borelli V, Lucioli J, Furlan FH, Hoepers PG, Roveda JF, Traverso SD, et al. Fatal onion (Allium cepa) toxicosis in water buffalo (Bubalus bubalis). J Vet Diagn Invest. 2009;21(3):402-5.

27. Aslani MR, Mohri M, Movassaghi AR. Heinz body anemia associated with onion (Allium cepa) toxicosis in a flock of sheep. Comp Clin Pathol. 2005;14(2):118-20.

28. Thorp F, Harshfield GS. Onion poisoning of horses. J Am Vet Med Assoc. 1939; 94(1):52-3.

29. Pierce KR, Joyce JR, England RB, Jones LP. Acute hemolytic anemia caused by wild onion poisoning in horses. J Am Vet Med Assoc. 1972;160(3):323-7.

30. Tang X, Xia Z, Yu J. An experimental study of hemolysis induced by onion (Allium cepa) poisoning in dogs. J Vet Pharmacol Ther. 2008;31(2):143-9.

31. Kay JM. Onion toxicity in a dog. Mod Vet Pract. 1983;64(6):477-8.

32. Fenwick GR, Hanley AB. Allium species poisoning. Vet Rec. 1985;166(1):28.

33. Houston DM, Myers SL. A review of Heinz-body anemia in the dog induced by toxins. Vet Hum Toxicol. 1993;35(2):158-61.

34. Gault G, Berny P, Lorgue G. Toxic plants for companion animals (in French). Recueil de Medicine Veterinaire. 1995;171(1):171-6.
35. Munday R, Munday JS, Munday CM. Comparative effects of mono-, di-, tri-, and tetrasulfides derived from plants of the Allium family: redox cycling in vitro and hemolytic activity and phase 2 enzyme induction in vivo. Free Radic Biol Med. 2003; 34(9):1200-11.

36. Yamato O, Hayashi $M$, Yamasaki M, Maede Y. Induction of onion-induced haemolytic anemia in dogs with sodium n-propylthiosulphate. Vet Rec. 1998; 142(9):216-9.

37. Kovalkovičová N, Šutiaková I, Pistl J, Šutiak V. Some food toxic for pets. Interdisc Toxicol. 2009;2(3):16976.

38. Nakamura K, Watanabe M, Sawai-Tanimoto S, Ikeda T. A low catalase activity in dog erythrocytes is due to a very low content of catalase protein despite having a normal specific activity. Int J Biochem Cell Biol. 1998;30(7):823-31.

39. Harvey JR, Kaneko JJ. Oxidation of human and animal haemoglobins with ascorbate, acetylphenylhydrazine, nitrite, and hydrogen peroxide. Br J Haematol. 1976; 32(2):193-203.

40. Ogawa E, Akahori F, Kobayashi K. In vitro studies on the breakdown of canine erythrocytes exposed to the onion extract. Nippon Juigaku Zasshi. 1985;47(5):71929.

41. Yamato O, Hayashi M, Kasai E, Tajima M, Yamasaki M, Maede Y. Reduced glutathione accelerates the oxidative damage produced by sodium n-propylthiosulfate, one of the causative agents of onion-induced hemolytic anemia in dogs. Biochim Biophys Acta. 1999;1427(2):175-82.

42. Harvey JW. Congenital erythrocyte enzyme deficiencies. Vet Clin North Am Small Anim Pract. 1996;26(5):1003-11.

43. Harvey JW. Pathogenesis, laboratory diagnosis, and clinical implications of erythrocyte enzyme deficiencies in dogs, cats, and horses. Vet Clin Pathol. 2006; 35(2):144-56.

44. Ogawa E, Kawakami A, Yagi T, Amaya T, Fujise H, Takahashi R. Oxidative damage to the membrane of canine erythrocytes with inherited high $\mathrm{Na}, \mathrm{K}$-ATPase activity. J Vet Med Sci. 1992;54(1):57-62.

45. Bloom JC, Brandt JT. Toxic responses of the blood. In: Klaasen CD, editor. Casarett and Doull's toxicology: the basic science of poisons. New York: McGraw-Hill Book Company; 2001. p. 389-418.

46. Lee KW, Yamato O, Tajima M, Kuraoka M, Omae $\mathrm{S}$, Maede Y. Hematologic changes associated with the appearance of eccentrocytes after intragastric administration of garlic extract to dogs. Am J Vet Res. 2000;61(11):1446-50.

47. Simmons DM. Onion breath. Vet Tech. 2001;22(8):4247.

48. Thrall MA. Veterinary hematology and clinical chemistry. Philadelphia: Lippincott Williams \& Wilkins; 2004. 618 p.

49. Cope RB. Allium species poisoning in dogs and cats. Vet Med. 2005;100(8):562-6.

50. Malik ZA, Siddiqui S. Hypotensive effect of freezedried garlic (Allium sativum) sap in dog. J Pak Med Assoc. 1981;31(1):12-3. 
51. Martin N, Bardisa L, Pantoja C, Román R, Vargas M. Experimental cardiovascular depressant effects of garlic (Allium sativum) dialysate. J Ethnopharmacol. 1992;37(2):145-9.

52. Mayeux PR, Agrawal KC, Tou JS, King BT, Lippton HL, Hyman AL, et al. The pharmacological effects of allicin, a constituent of garlic oil. Agents Actions. 1998; 25(1-2):182-90.

53. Apitz-Castro R, Badimon JJ, Badimon L. Effect of ajoene, the major antiplatelet compound from garlic, on platelet thrombus formation. Thromb Res. 1992;68(2):145-55.

54. Hoshino T, Kashimoto N, Kasuga S. Effects of garlic preparations on the gastrointestinal mucosa. J Nutr. 2001;131(3s):1109S-13S.

55. Yamoto O, Maede Y. Susceptibility to onion-induced hemolysis in dogs with hereditary high erythrocyte reduced glutathione and potassium concentrations. Am J Vet Res. 1992;53(1):134-7.

56. Smith JE, Ryer K, Wallace L. Glucose-6-phosphate dehydrogenase deficiency in a dog. Enzyme. 1976;21(4): 379-82.

57. Robertson JE, Christopher MM, Rogers QR. Heinz body formation in cats fed baby food containing onion powder. J Am Vet Med Assoc. 1998;212(8):1260-6.
58. Stalker MJ, Hayes MAT. Liver and biliary system. In: Maxie MG, editor. Jubb, Kennedy, and Palmer's pathology of domestic animals. 5th ed. Philadelphia: Elsevier Saunders; 2007. vol. 2. p. 297-388.

59. Valli VE. Hematopoietic system. In: Maxie MG, editor. Jubb, Kennedy, and Palmer's pathology of domestic animals. $5^{\text {th }}$ ed. Philadelphia: Elsevier Saunders; 2007. vol. 3. p. 107-324.

60. Gandini G, Bettini G, Pietra M, Mandrioli L, Carpenè E. Clinical and pathological findings of acute zinc intoxication in a puppy. J Small Anim Pract. 2002;43(12):539-42.

61. Hill AS, O’Neill S, Rogers QR, Christopher MM. Antioxidant prevention of Heinz body formation and oxidative injury in cats. Am J Vet Res. 2001;62(3):3704.

62. Bexfield N, Archer J, Herrtage M. Heinz body haemolytic anemia in a dog secondary to ingestion of a zinc toy: a case report. Vet J. 2007;174(2):414-7.

63. Christopher MM, Perman V, Eaton JW. Contribution of propylene glycol-induced Heinz body formation to anemia in cats. J Am Vet Med Assoc. 1989;194(8):104556. 